\title{
Supporting Programme Teams to Develop Sequencing in Higher Education Curricula
}

\author{
Roisin Donnelly \\ Technological University Dublin, roisin.donnelly@tudublin.ie \\ Geraldine O’Neill \\ University College Dublin \\ Marian Fitzmaurice \\ University of Dublin, Trinity College
}

Follow this and additional works at: https://arrow.tudublin.ie/ltcart

Part of the Education Commons

\section{Recommended Citation}

O’Neill, G., Donnelly, R., Fitzmaurice, M. (2013): Supporting programme teams to develop sequencing in higher education curricula, International Journal for Academic Development. DOI:10.1080/ 1360144X.2013.867266

This Article is brought to you for free and open access by the Learning Teaching \& Assessment at ARROW@TU Dublin. It has been accepted for inclusion in Articles by an authorized administrator of ARROW@TU Dublin. For more information, please contact arrow.admin@tudublin.ie, aisling.coyne@tudublin.ie, gerard.connolly@tudublin.ie.

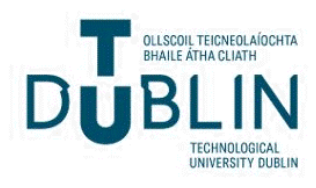


This article was downloaded by: [Dublin Institute of Technology]

On: 07 January 2014, At: 03:58

Publisher: Routledge

Informa Ltd Registered in England and Wales Registered Number: 1072954 Registered

office: Mortimer House, 37-41 Mortimer Street, London W1T 3J H, UK

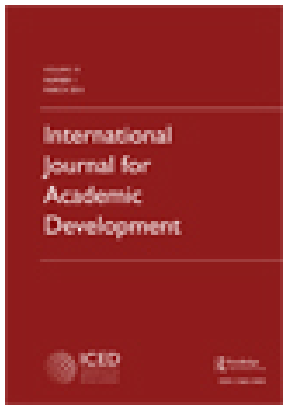

\section{International J ournal for Academic Development}

Publication details, including instructions for authors and subscription information:

http:// www. tandfonline.com/loi/ rija20

\section{Supporting programme teams to develop sequencing in higher education curricula}

Geraldine $0^{\prime}$ Neill $^{a}$, Roisin Donnelly ${ }^{b} \&$ Marian Fitzmaurice ${ }^{c}$

a UCD Teaching \& Learning, University College Dublin, Dublin, Ireland

${ }^{b}$ The Learning, Teaching and Technology Centre, Dublin Institute of Technology, Dublin, Ireland

${ }^{c}$ Centre for Academic Practice and eLearning (CAPSL), Trinity College, University of Dublin, Dublin, Ireland Published online: 11 Dec 2013.

To cite this article: Geraldine O' Neill, Roisin Donnelly \& Marian Fitzmaurice, International J ournal for Academic Development (2013): Supporting programme teams to develop sequencing in higher education curricula, International J ournal for Academic Development, DOI:

10.1080/ 1360144X.2013.867266

To link to this article: http:// dx.doi.org/ 10.1080/ 1360144X.2013.867266

\section{PLEASE SCROLL DOWN FOR ARTICLE}

Taylor \& Francis makes every effort to ensure the accuracy of all the information (the "Content") contained in the publications on our platform. However, Taylor \& Francis, our agents, and our licensors make no representations or warranties whatsoever as to the accuracy, completeness, or suitability for any purpose of the Content. Any opinions and views expressed in this publication are the opinions and views of the authors, and are not the views of or endorsed by Taylor \& Francis. The accuracy of the Content should not be relied upon and should be independently verified with primary sources of information. Taylor and Francis shall not be liable for any losses, actions, claims, proceedings, demands, costs, expenses, damages, and other liabilities whatsoever or howsoever caused arising directly or indirectly in connection with, in relation to or arising out of the use of the Content.

This article may be used for research, teaching, and private study purposes. Any substantial or systematic reproduction, redistribution, reselling, loan, sub-licensing, systematic supply, or distribution in any form to anyone is expressly forbidden. Terms \& 

and-conditions 


\title{
Supporting programme teams to develop sequencing in higher education curricula
}

\author{
Geraldine O’Neill $^{\mathrm{a} *}$, Roisin Donnelly ${ }^{\mathrm{b}}$ and Marian Fitzmaurice ${ }^{\mathrm{c}}$ \\ ${ }^{a} U C D$ Teaching \& Learning, University College Dublin, Dublin, Ireland; ${ }^{b}$ The Learning, \\ Teaching and Technology Centre, Dublin Institute of Technology, Dublin, Ireland; ' Centre \\ for Academic Practice and eLearning (CAPSL), Trinity College, University of Dublin, \\ Dublin, Ireland
}

(Received 10 March 2013; final version received 1 August 2013)

\begin{abstract}
Curriculum sequencing is central to promoting a coherent student experience. Yet in the higher education context, the concept and practice of curriculum sequencing have not been fully explored. This research examined how seven programme teams approached the issue of sequencing across two Irish higher education institutions. A phenomenological approach was used to explore actions, challenges, and enhancers to sequencing. The three key themes emerging were: developing a collective philosophy; communicating the sequencing clearly; and developing strong building blocks. Ideas are presented on how academic developers can work with academic staff to improve sequencing in their curricula.
\end{abstract}

Keywords: academic development; challenges; curriculum; programme teams; sequencing

\section{Introduction}

Higher education has expanded and diversified with changes in the student body, increased pressure from government on costs and procedures, and an array of transformations in terms of curriculum. Some of these changes have created a more fragmented presentation of the curriculum. Trow (1992) suggested this fragmentation was related to modularisation, semesterisation, credit accumulation, credit transfer, franchising, and the accreditation of prior learning. More recently, Hubball and Gold (2007) argue that undergraduate curricula are complex and multifaceted processes that are shaped by many factors (social, political, economic, organisational, cultural, and individual). Indeed such curricula are at various stages of development - and perhaps reform - and they may involve people at several institutional levels in the teaching and learning context (administrators, curriculum development committee members and support teams, teachers, and students). As a result, the potential for both fragmentation and disjointed thinking when it comes to curriculum design is not inconsiderable. From an academic development perspective, Blackmore and Blackwell (2006, p. 373) describe this as 'a background of fragmentation.'

The introduction of the modular system - a key driver in Irish and other international contexts - has been a major transformation for undergraduate

*Corresponding author. Email: geraldine.m.oneill@ucd.ie 
education. Many of the programmes currently modularised may be a dissected version of the previous degree programme. Modular programmes are also criticised for an apparent lack of concern for the overall coherence, sequencing, and relevance of the content in a student's programme of study (Brecher, 2005).

In addition, certain practices around the sequencing of teaching, learning, and assessment activities at undergraduate level have been driven by contextual factors rather than considered curriculum planning. For example, the economics of curriculum design has meant that large classes of students in the early years of a degree experience more lecture-based teaching, whereas project work is more easily done in the smaller classes in the later years. Academic staff in higher education are disciplinary experts but their decisions about the curriculum are not always the result of the systematic use of a clearly thought-out set of ideas; rather they can be strongly influenced by contexts beyond their immediate control. Curriculum creators therefore need guidance, sometimes through academic development support, in how to select and organise the essence of a curriculum.

One of the challenges here for academics is that there are contrasting conceptualisations of the curriculum, such as constructive alignment (Biggs \& Tang, 2007), the hidden curriculum (Trow, 1992), the blended curriculum (Littlejohn \& Pegler, 2007), and the students' learning experience (Fink, 2003). Fraser and Bosanquet (2006) give a comprehensive overview of different perceptions (categories) of 'curriculum' and how these relate to the product and/or process models of curriculum; our own philosophy of curriculum is closest to Fraser and Bosanquet's (2006) 'process' categories, which include the students' experience of learning.

Over a decade ago, Harden and Stamper (1999) argued that organisation of the order of content and the overall structure of the curriculum was a relatively neglected area of research. More recently, Ornstein and Hunkins (2009) highlighted sequencing as one of the six key design dimensions (namely scope, sequence, integration, continuity, articulation, and balance) that curriculum creators and developers need to explore. Sequencing of the curriculum therefore appears to be both a gap in the literature and in our academic development practice and knowledge. As sequencing is an iterative process and involves various people, the views of the programme team were considered vital. (Teams were the key academic staff - sometimes from a range of disciplines - who were responsible for the programme design and implementation.)

For the purposes of this study, we decided to explore what actions, challenges, and enhancers exist for programme teams in sequencing their curricula. Our findings should help us and other academic developers to support staff in this area. Due to the complexity of sequencing, we decided to focus on the traditional three- or four-year undergraduate curriculum.

\section{Literature review}

\section{Introduction to sequencing}

Sequencing in a curriculum is often described as the vertical integration of students' experiences (Vidic \& Weitlauf, 2002) which can be both from 'disciplinary knowledge' and the 'learning experience.' Modularisation challenges some of this vertical integration and as a backlash to it, more recent literature has focused on enhancement and actions to improve sequencing in a programme, for example, 
through curriculum mapping (Sumsion \& Goodfellow, 2004) or the use of spiral curriculum models (Harden \& Stamper, 1999). Interestingly some of the blended learning literature, although more focused on sequencing within a module, places 'learning experiences' at the heart of the sequencing, as it situates learning tasks/ activities at the centre of the design (Garrison \& Vaughan, 2008; Littlejohn \& Pegler, 2007). In contrast, much of the literature emphasises a 'product focus' (Fraser \& Bosanquet, 2006) or 'disciplinary knowledge' sequencing. And while the literature can assist academic staff in sequencing their programmes (Fink, 2003; Toohey, 1999), it is not conclusive and requires further consideration. For example, there is a long-standing controversy over whether the sequence of the disciplinary knowledge should be based on the logic of the subject or the way in which individuals process knowledge (Ornstein \& Hunkins, 2009).

Programme teams could consider many different forms of sequencing: simple to complex, easy to difficult, prerequisite learning, whole to parts and vice versa, chronological, developmental, and known to unknown. Toohey (1999) adds to this complexity by outlining how disciplinary knowledge can be sequenced by time, spatial relationships, species, forms of expression, functional systems processes, or a combination of some of these. Knowing about these sequencing algorithms is one thing, but deciding collectively on which to use from the following array is another.

A relatively recent example of an approach to sequencing disciplinary knowledge is 'threshold concepts' (Land, Meyer, \& Smith, 2008). For some time, academic staff have recognised that some students 'get stuck' at particular points in a discipline's curriculum (in other words 'troublesome knowledge'), whilst others grasp concepts with comparative ease. Land et al. (2008) have explored what staff can do in relation to their programme design to assist students in overcoming such barriers to learning and argue that programmes should be sequenced by revisiting these 'troublesome' threshold concepts in the curriculum.

Several important curriculum frameworks also address the sequencing of disciplinary knowledge in the curriculum: linear, spiral, thematic, and student-centred sequencing, each of which we will now briefly explain. Linear sequencing might typically involve arranging curriculum modules according to levels of difficulty or increasing complexity (Toohey, 1999). In a spiral curriculum sequence, the different areas or topics that make up the curriculum are studied more than once (Harden \& Stamper, 1999); at first, they are covered at a relatively superficial level, and then they are revisited so that they can be explored more critically, usually over a longer period of time. In thematic sequencing, core or key themes give a strong structure throughout the programme as a whole (Neary, 2002). These central themes would be seen as underpinning all of the work that students do while studying the curriculum. Another curriculum model focuses on how students negotiate their own curriculum, a more student-centred approach to sequencing. This is endorsed by Barnett and Coate (2005) who suggest that in an age of complexity, effective curriculum design lies in the imaginative creation of structured-educational spaces in which the students' own energies are likely to be prompted.

Some frameworks, such as the 'backward design' approach, also assist in actions to sequence learning and assessment (O'Neill, 2010). The popularity of 'backward design,' often used with graduate attributes, has prompted the mapping of assessments across the years of a programme. 


\section{Challenges to sequencing}

Despite these enhancers and drivers for change, programme teams face specific challenges both at the institutional and programme levels in sequencing the undergraduate curriculum. In the literature, some of the key challenges to coherent sequencing include the increasing diversity of stakeholders (Sundberg et al., 2011), institutional structures (Stark, 2000), staff training (Fink, 2003), and lack of shared understanding of the concept of the curriculum (Fraser \& Bosanquet, 2006). Curriculum innovation can also be problematic. For instance, Stephenson and Yorke (1998) argue that radical change is difficult to introduce in institutions where most of the administrative, managerial, financial, and quality assurance infrastructures are geared to more traditional programme designs.

In Ireland, as elsewhere, there is growing emphasis on wider stakeholder engagement in programmes (Hunt, 2011), especially at the community and employer level. Fraser and Bosanquet describe that this involves engaging with 'significant others from outside the university community' (Fraser \& Bosanquet, 2006, p. 276), however not all staff include this in their understanding of curriculum. The institutional barriers of structures, culture, systems, and processes can arguably hinder the transformation of the curriculum design process and adaptability of programme provision to a changing market. Beetham (2009) reports that curriculum design and development are the core functions of institutions, occupying substantial human resources, enacting institutional identities and values, and constituting a major opportunity to deliver on the institutional mission. She argues, however, that partly because of the unique value of the curriculum at accrediting institutions, systems for developing it are usually concerned with quality and due process rather than flexibility and responsiveness, with the consequence of a lack of focus on sequencing.

Fink (2003) stresses that 'faculty knowledge about course design is the most significant bottleneck to better teaching and learning in higher education' (Fink, 2003, p. 24), meanwhile Ziegenfuss (2007) argues that a lack of research exists on how programme teams in higher education design and develop the courses they teach. So, although we highlighted earlier that curriculum frameworks can assist staff in sequencing, the opportunity for staff to engage with this knowledge or access research in this area can be a significant challenge.

\section{Methodology \\ Context and research approach}

This study was initiated because of the ongoing challenges facing us - and other academic developers - in supporting programme teams across different disciplines with curriculum sequencing. Healey, Bradford, Roberts, and Knight (2011) and Jenkins (1996) highlight the need for academic developers to work collaboratively with particular curricular and pedagogic concerns of the disciplines. The study was carried out in our own workplaces, a research-intensive university with approximately 22,000 students across seven colleges and an institute of technology with approximately 19,000 students across four colleges. Although the study crossed two institutions, our intention was not to conduct a comparison of practice across these contexts, but to try to represent two key contexts of practice for academic developers in higher education.

We used a phenomenological qualitative approach in an 'attempt to understand the meaning of events and interactions to ordinary people in particular situations' 
(Bogdan \& Biklen, 1998, p. 23). Seven programme teams were purposefully sampled to give some diversity of disciplines (Berg, 2001). The sample consisted of engineering, chemistry, international tourism, and business from the institute of technology and psychology, modern languages, and civil engineering from the research-intensive university.

\section{Data collection and analysis}

As programme teams are central in the design of curricula (Healey et al., 2011), we decided on focus groups representing each programme team for appropriate data-gathering. Willig (2001) described these as 'pre-existing focus groups' as the participants are already work colleagues. Twenty-five individuals participated in one of seven 90-minute, semi-structured focus groups, each group ranging from three to six people. Interview questions were based on the research objectives (namely actions, challenges, and enhancers to sequencing in a programme). The rationale and purpose of the study were explained to participants, who then read and signed an informed consent document (Berg, 2001).

Focus groups were recorded and coded. The coding was cross-checked by the three researchers to provide a credibility check on the data (Willig, 2001) and the relationships between the themes and units of analysis were revisited on a few occasions to consider the 'importance of fit' - one of the criteria for evaluating good qualitative research (Willig, 2001), emphasising that the themes and units generated by the researcher should fit the data.

During the coding process, 201 individual sub-themes emerged (Level 1 coding). These were initially coded under the three original pre-determined themes of enhancers, challenges, and actions to sequencing in a curriculum. In exploring these Level 1 codes, we identified considerable repetition of sub-themes and these were further reduced to 45 Level 2 coding sub-themes. There was often a strong relation between what people described as enhancers (e.g. existence of a progressive team) and the opposite challenge (limited team approach) and at times this was also supported by remedial action (e.g. develop a new committee). In analysing and reanalysing the data, three key themes emerged: developing a collective philosophy; communicating the sequencing to students and staff; and developing strong building blocks. These three emergent themes accounted for nearly all of the 45 Level 2 sub-themes and provide the basis for organising the findings and discussion.

\section{Findings}

\section{Theme 1: developing a collective philosophy}

Modularisation was identified as a challenge to sequencing which (along with other challenges, such as staff having individual teaching philosophies) contributed to an emerging theme related to the development of a programme's collective philosophy. The existence of a strong team was seen as key to forming a view or philosophy of the programme and through formal ('committees') or informal contexts ('informal talk'), sequencing of the curriculum was given attention. Psychology in particular believed that a collective view was central to decisions around sequencing, but this, they noted, did not equate with all having the same approach to teaching, but was about sharing their views. 
Most programme teams recognised that developing this collective view of the curriculum was important for discussion around sequencing; however some highlighted that it was easier in more moderately sized schools or departments. Often this collective view was developed in scheduled meetings, and staff noted that it was valuable to articulate progress in teaching and learning as it occurred, in other words, sequencing in real-time:

The natural times (to meet) are September and half-way through the semester; it tends to be from the point of view of one person wanting to know how far someone else got in a previous year. We have a good relationship in that we show each other the lecture notes and problems that we give students, and sometimes, when starting a new topic, I ask 'Can you give me the problems that you set?' and it is a good starting point. We have a very open relationship. (Chemistry)

While the development of a collective philosophy among staff aided the sequencing process, it was also noted that the curriculum can be disjointed for students if they do not have a strong programme identity. This was particularly identified as a challenge in two types of programmes: (a) Those with many modules shared with other disciplines:

Our biggest challenge is student identity on the programme - we have done a lot of thinking about that. We have to work very hard so they feel they have a core identity - that is a challenge. We do not want it to be a disjointed experience. (International Tourism)

And (b) 'difficult' subjects:

We have found that our students regard chemistry as a difficult subject and many of the concepts are inexplicable without the use of analogies or models. This is the challenge that we have to address in our planning. We have introduced student-driven practicals as an example of a strategy to promote learning through curriculum design and a sequence of design activities to provide the students with opportunities to develop authentic scientific inquiry skills. (Chemistry)

\section{Theme 2: communication of sequencing to students and staff}

To improve sequencing, it was not sufficient simply to have a collective philosophy of the programme; the sequencing also has to be communicated to staff and students. Clear communication and articulation of the programme structure gave students some control in knowing how the sequencing of their disciplinary knowledge was best developed; this was particularly important where students had plenty of choice in their module selection, for example in the arts programmes. Poor sequencing for students in these contexts was attributed to students making poor choices, possibly due to the lack of a communicated overview or a lack of engagement with that overview:

The challenge with students when they come in is that they don't see any coherence at all in the programme ... Some don't even see the full picture in third year. They don't see the links. (International Tourism)

Staff highlighted that students' awareness of sequencing could be facilitated by improving advice and guidance to students. For example, as one staff member noted, 
'Students need to know that some combinations are not good choices' (Modern Languages).

Staff communication regarding programme sequencing was dependent on very pragmatic issues, such as space to meet, but was also enhanced by the existence of policies at the school or programme level.

\section{Theme 3: developing strong building blocks}

The third theme related to developing building blocks in a curriculum in order to give structure to sequencing. Some staff mentioned the idea of ensuring that there were sufficient core modules that could then be built on to develop transparent pathways for students; examples included core professional modules in the early years of a programme (engineering, psychology) and embedding core laboratories into the timetable (science-orientated curricula). In some disciplines, such as languages, it was particularly important to develop strong building blocks that required clear prerequisite modules to facilitate grouping students with similar skills sets.

Some schools were able to articulate the types of sequencing of these building blocks. For example, some mentioned that they generally sequence disciplinary knowledge from simple to complex ideas in the curriculum (linear sequencing), whereas several engineering programmes sequenced from material to theory to design. International Tourism gave an example of their own challenges and described some different building blocks (such as management, technological, and operational skills):

Our main challenge in planning the curriculum is to enable our students to be sufficiently motivated to cultivate their competitiveness, widen their career prospects, and receive skills training across the core and elective modules. To do all this, maintaining our strong industry links and integrating these to all stages of the programme is vital. In planning for a challenging programme, we aim to achieve a balance in sequencing the necessary management, technological, and operational skills needed by the students.

Despite challenges, there were some examples of how staff had achieved a collective view on the sequence of teaching and learning approaches:

We think through the teaching and learning sequence. We even have a policy document on assessment and we look at the kinds of assessment that are appropriate for the three years, e.g. when could you begin to introduce group work versus individual assignment. I think particularly in labs, the beginning is introducing them to critical thinking in some skills and the second semester of labs is getting them to design something on their own. In fact that leads to the project which is an independent piece of work, under supervision. (Psychology)

One of strong sub-themes to emerge in relation to building blocks in sequencing the curriculum was institutional structure and policies. Given that both institutions were in a post-modularisation period, some of these structural and policy challenges were related to issues such as schools not having much input into the first year of the curriculum, flattening of stages, students coming into modules from multiple routes, and a lack of structure in elective modules. It appeared easier to develop strong building blocks where the impetus came from external drivers such as professional accreditation or European competency frameworks. 
In summary, despite many challenges to sequencing, academic staff were attempting to develop sequencing in their programmes. It was most challenging where the teams struggled to develop a collective view of the programme. Developing building blocks was key, but approaches varied, and the communication of the sequencing to staff and students was particularly vital where programmes had high levels of student choice.

\section{Discussion and ideas for consideration}

In this discussion, we elaborate on the three key themes from the findings. In addition, based on these findings and on the related curriculum design literature, we will present some ideas for academic developers to consider in partnership with staff involved in curriculum sequencing.

\section{Towards a collective curriculum philosophy}

Philosophy is the starting point in any curriculum and is the basis for all subsequent decisions regarding curriculum sequencing. Schönwetter, Sokal, Friesen, and Taylor (2002) discuss the synergy between self, discipline, and institutional contexts for academic staff as part of philosophy development, and this hints at the complexity of developing a collective curriculum philosophy.

While there has been some attention in the literature to developing an educational philosophy at the beginning of a curriculum design process (Diamond, 1998; Errington, 2004; O'Neill, 2010; Toohey, 1999), there is very little exploration of how this philosophy can be maintained over time. Toohey (1999) describes this step as sorting out the beliefs and values of the team involved in curriculum design. Errington (2004, p. 40) reports that it encompasses views on "what teachers believe they should be teaching, what learners should be learning and the respective roles of teachers and learners in pursuing both.' In 2010, O'Neill outlined how this step was a key starting point for academic developers working with academic staff in curriculum planning, both at the level of programme and module design.

Stark (2000, p. 417) maintains that 'the views teachers held about the nature of their discipline are intricately linked with their beliefs about the purpose of education,' arguing that many staff draw their beliefs on teaching and learning from their disciplinary base. Designing a programme of study requires the combined efforts of many academic staff and students, often from diverse disciplines. It is therefore essential in planning the sequencing in a programme that a team engages in a discussion on the beliefs and values espoused by the programme to assist in developing a logical sequence of both teaching approaches and disciplinary knowledge. Students should be co-creators of this educational philosophy, if we were to advocate our own curriculum philosophy. Whereas this activity is often quite present in the early stage development of a new programme (Diamond, 1998; Toohey, 1999), there appears to be very little reference to the revisiting of this step as curriculum develops and changes. It may be that the quality assurance process and procedures required of staff in the early stages of curriculum design expect that a team of stakeholders will develop a collective educational philosophy (Diamond, 1998; Errington, 2004; Toohey, 1999). However, this philosophy can be difficult to maintain as curriculum changes, contextual influences shift (Stark, 2000), and academic staff change. Maintaining this collective view over the duration of a curriculum can be 
problematic, in particular - as noted in the findings - where there is no interim institutional or professional driver. This can impact the sequencing of discipline knowledge and of teaching/learning and assessment activities.

\section{Ideas for consideration}

- There is a need in our curriculum design work to assist programme teams in creating and sustaining an ongoing curriculum philosophy. This can be created in programme team/discipline-oriented workshops and supplemented by some creative visual approaches (see, for instance Healey et al., 2011). Students should be involved in this process (Fraser \& Bosanquet, 2006).

- As no single model of curriculum sequencing was being advocated, programme teams should be encouraged to consider their most suitable curriculum sequencing model.

Having a collective philosophy to assist in curriculum sequencing has not featured widely in the existing literature, and consequently is a new contribution from this study. Without a collective philosophy, the programme team may struggle with the decision-making aspect of how the vertical integration of students' experiences will be built (Vidic \& Weitlauf, 2002).

\section{Developing curricular building blocks}

There has been some attention in the literature to approaches to the sequencing of knowledge, for example, theme-based (Neary, 2002), spiral (Harden \& Stamper, 1999), and simple to complex (Toohey, 1999). Interestingly in this current study very few of these terms were alluded to, possibly due to unfamiliarity with them. However, there was a shared understanding of the idea of curricular building blocks. These were highlighted as very important to the process of designing undergraduate programmes.

Based on the findings, there is a need across all types of programmes for a decision on what is considered 'core.' Staff need to examine whether there are essential foundations that are requisite in advancing towards mastery.

Academic staff need to know how best to establish how a shift can occur from the more simple 'building blocks' to understanding more complex principles in the disciplines. Neary (2002, p. 109) highlights this challenge when revisiting or building concepts to 'synthesise and sequence the elements in a way which offers a stimulating challenge to learners at each stage.' In addition, Popham (2007) argues that isolating and sequencing the building blocks underlying students' attainment of a challenging curricular aim requires rigorous cerebral effort.

In this study, these building blocks varied. Disciplines such as engineering organised the sequence in relation to the logic of the disciplines, whereas it appears that the simple-to-complex approach was frequently used by other programmes. Although this was a small sample of programmes, there was a lack of awareness of other approaches, such as starting with complex problems, organising by themes, or by threshold concepts.

The Irish National Strategy for Higher Education to 2030 argues for the major role that higher education will play in developing Irish society and a 
knowledge-based economy over the coming decades; it also calls for greater emphasis in the undergraduate curriculum on generic skills that are required in the workplace and for active citizenship (Hunt, 2011). However, the programme teams were aware of tensions between the drive for broadening the curriculum (Hunt, 2011; Robinson, 2011) and a call for more curricular cohesion and integration (Fink, 2003; Ornstein \& Hunkins, 2009) as evidenced in both the UK and USA higher education experience. Either approach would require careful alignment of the curriculum to the programme's outcomes (Biggs \& Tang, 2007).

\section{Ideas for consideration}

- Academic developers can facilitate staff awareness of sequencing terminology and critique different frameworks. Possible activities include: developing accessible resources and/or workshops on outcomes-based designs, spiral curriculum, threshold concepts, and so on.

- In light of the international trend to a broader curriculum agenda, staff may need support to move away from overemphasis on specific discipline knowledge to more process models of curriculum sequencing (Fraser \& Bosanquet, 2006), in other words, a stronger emphasis on the sequencing of the student learning experience as the key building block.

- Academic developers have a role to play in developing and refining institutional policies that may be hindering curriculum sequencing.

\section{Improving communication between staff and students in relation to sequencing}

A central finding of this study is the importance of having what Diamond (1998) called transparent articulation of the programme. Clearly articulating the sequence in a programme was considered key in programmes with high levels of student choice. Methods to enable this include using curriculum maps to organise the programme, and using a timeline for planning to promote communication and collaboration among the programme team. Curriculum mapping can help both staff and students by visually displaying the main elements of the curriculum and the relationships between them (Healey et al., 2011). It helps academic staff exchange information about the sequence of what is being taught.

While mapping has been successfully identified as an analysis and planning tool, in this current study, its usefulness comes to the fore in improving communication about sequencing between different members of the programme team (Sumsion \& Goodfellow, 2004). It allows the team to review the curriculum to check for unnecessary redundancies, inconsistencies, misalignments, weaknesses, and gaps. Also important is its use for identifying opportunities for integration among disciplines as well as ascertaining what students have learned, allowing academic staff to focus on building on previous knowledge or students' learning experiences.

The potential to explore sequencing in different types of programme meetings (formal/informal) features strongly in this research. Whether developing sequencing in a new programme or modifying an existing one, regular meetings with student and staff representatives are essential. Ornstein and Hunkins (2009) emphasise the importance of horizontal communication (between people at the same level of hierarchy) and vertical communication (between people at different levels of the school 
hierarchy) in curriculum design. They stress that communication flows more easily between 'people who consider themselves equals and who are equally involved in curriculum change' (Ornstein \& Hunkins, 2009, p. 251). Programme committees are useful sources of information about sequencing in the programme and help increase ownership of the curriculum. Arguably the most significant role in enhancing communication on the curriculum relates to how it is communicated to students so that they can make 'good sequencing choices.' This has the potential to lead to student empowerment so that they can make decisions such as how they will distribute their effort between their modules and what subsequent effect this will have. Student empowerment is essential in Fraser and Bosanquet's (2006) final category of curriculum.

\section{Ideas for consideration}

- To encourage the use of curriculum mapping tools for the purpose of making sequencing transparent to students and between staff on the programme team.

- To assist staff in developing communication approaches that highlight the sequencing in their curriculum, in particular in disciplines where students have a high level of choice.

\section{Conclusion}

This research has sought to understand the experience of seven programme teams in sequencing their curricula and the key role sequencing plays in their curriculum design. The study focused on the enhancers and barriers that influence the design of sequencing and what actions the teams employed to improve sequencing. We anticipate that the ideas for consideration in this study will offer clearer ways forward both for programme teams who design curricula and the academic developers who support them. Although the small sample size in this study limits generalisability of the findings, we believe critical aspects of the role of sequencing identified by the programme teams here can be applied to other disciplines. Furthermore additional research needs to be conducted, in particular to represent the student voice, which would reflect our own philosophy of a more process-oriented model of curriculum (Fraser \& Bosanquet, 2006). Continuing this research is imperative for building the evidence base for curriculum change, so that we are prepared for the changing context of curricula in the twenty-first century. This study has also offered us an opportunity to reflect as academic developers on what future approaches we might take to proactively promote sequencing of the curriculum in our institutions.

\section{Acknowledgements}

We would like to thank to the academic staff who contributed to the focus group discussions in this research.

\section{Notes on contributors}

Geraldine O'Neill is a senior lecturer in educational development in UCD Teaching \& Learning, University College Dublin, Ireland. She has been an educational developer for 10 years. Developing a more coherent approach to curriculum design has been one of the key focuses of her work, research, and contribution to institutional projects. 
Roisin Donnelly is Programme Chair of the MSc Applied eLearning, and the MA in higher education in the Dublin Institute of Technology, and a fellow of the Higher Education Academy. In her current role, she delivers consultancies on topics in learning development and has published on her teaching and research interests, including supporting virtual communities, curriculum design, blended problem-based learning, and ePortfolios.

Marian Fitzmaurice is a visiting research fellow in the Centre for Academic Practice and eLearning in University of Dublin, Trinity College. She has worked as an educational developer and lectured in both Dublin Institute of Technology and the Institute of Technology, Carlow, and has published on topics including teaching in higher education, academic writing and publishing, curriculum design, narrative research, and professional identity.

\section{References}

Barnett, R., \& Coate, K. (2005). Engaging the curriculum in higher education. Maidenhead: SRHE \& Open University Press.

Beetham, H. (2009). Synthesis report: Baselining the institutional processes of curriculum design: JISC 'Institutional approaches to curriculum design' programme. Bristol: JISC. Retrieved from http://www.jisc.ac.uk/whatwedo/programmes/elearning/curriculumdesign.aspx

Berg, B. L. (2001). Qualitative research methods for the social sciences. London: Allyn \& Bacon.

Biggs, J., \& Tang, C. (2007). Teaching for quality learning at university: What the student does (3rd ed.). Maidenhead: Open University Press.

Blackmore, P., \& Blackwell, R. (2006). Strategic leadership in academic development. Studies in Higher Education, 31, 373-387.

Bogdan, R. C., \& Biklen, S. K. (1998). Qualitative research in education: An introduction to theory and methods (3rd ed.). London: Allyn \& Bacon.

Brecher, B. (2005). Complicity and modularisation: How universities were made safe for the market. Critical Quarterly, 47, 1-2.

Diamond, R. M. (1998). Designing and assessing courses and curricula: A practical guide. San Francisco, CA: Jossey-Bass.

Errington, E. (2004). The impact of teacher beliefs on flexible learning innovation: Some practices and possibilities for academic developers. Innovations in Education and Teaching International, 41, 39-47.

Fink, L. D. (2003). Creating significant learning experiences: An integrated approach to designing college courses. San Francisco, CA: Jossey-Bass.

Fraser, S., \& Bosanquet, A. (2006). The curriculum? That's just a unit outline, isn't it? Studies in Higher Education, 31, 269-284.

Garrison, D. R., \& Vaughan, N. D. (2008). Blended learning in higher education: Framework, principles, and guidelines. San Francisco, CA: Jossey-Bass.

Harden, R. M., \& Stamper, N. (1999). What is a spiral curriculum? Medical Teacher, 21, 141-143.

Healey, M., Bradford, M., Roberts, C., \& Knight, Y. (2011). Collaborative discipline-based curriculum change: Applying change academy processes at department level. International Journal of Academic Development, 18(1), 1-14.

Hubball, H., \& Gold, N. (2007). The scholarship of curriculum practice and undergraduate program reform: Theory-practice integration. Retrieved from http://www.cte.hawaii.edu/ handouts/HH_NG_Ch1_2.pdf

Hunt, C. (2011). National strategy for higher education to 2030: Report of the strategy group. Dublin: Department of Education and Skills. Retrieved from http://www.hea.ie/ sites/default/files/national_strategy_for_higher_education_2030.pdf

Jenkins, A. (1996). Discipline-based educational development. International Journal for Academic Development, 1, 50-62.

Land, R., Meyer, J. H. F., \& Smith, J. (2008). Threshold concepts within the disciplines. Rotterdam: Sense Publications.

Littlejohn, A., \& Pegler, C. (2007). Preparing for blended e-learning. New York, NY: Routledge. 
Neary, M. (2002). Curriculum studies in post compulsory and adult education: A teacher's and student teacher's study guide. Cheltenham: Nelson Thornes.

O'Neill, G. (2010). Initiating curriculum revision: Exploring the practices of educational developers. International Journal for Academic Development, 15, 61-71.

Ornstein, A. C., \& Hunkins, F. P. (2009). Curriculum foundations, principles and issues (5th ed.). Boston, MA: Allyn and Bacon.

Popham, W. J. (2007). The lowdown on learning progressions. The Prepared Graduate, 64, $83-84$.

Robinson, K. J. (2011). The rise of choice in the U.S. University and College: 1910-2005. Sociological Forum, 26, 601-622.

Schönwetter, D. J., Sokal, L., Friesen, M., \& Taylor, K. L. (2002). Teaching philosophies reconsidered: A conceptual model for the development and evaluation of teaching philosophy statements. International Journal for Academic Development, 7, 83-97.

Stark, J. S. (2000). Planning introductory college courses: Content, context and form. Instructional Science, 28, 413-438.

Stephenson, J., \& Yorke, M. (1998). Creating the conditions for the development of capability. In J. Stephenson \& M. Yorke (Eds.), Capability and quality in higher education (pp. 193-225). London: Kogan Page.

Sumsion, J., \& Goodfellow, J. (2004). Identifying generic skills through curriculum mapping: A critical evaluation. Higher Education Research and Development, 23, 329-346.

Sundberg, M. D., DeAngelis, P., Havens, K., Zorn-Arnold, B., Kramer, A. T., Holsinger, K., ... Stritch, L. (2011). Perceptions of strengths and deficiencies: Disconnects between graduate students and prospective employers. BioScience, 61, 133-138.

Toohey, S. (1999). Designing courses for higher education. Buckingham: SRHE and Open University Press.

Trow, M. (1992). Class, race and higher education in America. In E. Margolis (Ed.), The hidden curriculum in higher education (pp. 355-403). Cambridge: Cambridge University Press.

Vidic, B., \& Weitlauf, H. M. (2002). Horizontal and vertical integration of academic disciplines in the medical school curriculum. Clinical Anatomy, 15, 233-235.

Willig, C. (2001). Introducing qualitative research in psychology: Adventures in theory and method. Buckingham: Open University Press.

Ziegenfuss, D. (2007). A phenomenographic analysis of course design in the academy. Journal of Ethnographic \& Qualitative Research, 2, 70-79. 